\title{
Acoustic frequency for bubble size correlation using acoustic emissions
}

\author{
S. Husin ${ }^{1}$, A. Addali ${ }^{2} \&$ D. Mba $^{2}$ \\ ${ }^{1}$ Universiti Kuala Lumpur Malaysian Spanish Institute, Malaysia \\ ${ }^{2}$ Cranfield University, School of Engineering, UK
}

\begin{abstract}
In this study, a correlation between acoustic frequency and the bubble size of a single bubble burst at the free surface has been demonstrated. Bubble burst was used as it is an acoustically noisy process, independent parameter and potential source of AE in a liquid medium. An AE transducer was used to record sound as the bubble bursts at the free surface. The acoustic data were then processed to extract the bursting frequency associated with the bubble size. The frequency of the acoustic bursting has been shown to be related to the size of the bubble. The effects of liquid viscosity on acoustically determined bubble size has also been demonstrated.

Keywords: Acoustic Emission (AE), gas bubble, gas bubble burst, frequency spectra.
\end{abstract}

\section{Introduction}

Bubble burst characteristics-acoustic frequency can be used as a basis for interpreting bubble properties, particularly bubble size. Sound pressure detection from a single bubble burst at free surface is an important parameter for estimating bubble and liquid properties where the process is independent from external forces. Bubble bursting by its nature at a free surface is deemed useful for empirical parameter which is more accurate and detectable with an $\mathrm{AE}$ transducer. However, study of the acoustic frequency of a single bubble burst at free surface using AE technology is never attempted for bubble properties' determination, particularly for bubble sizing. This proposed technique is passive, can be employed either intrusively or non-invasively and is a rapid measurement technique. Furthermore, the robust acoustic transducer is more practical in 
hostile industrial or environmental flows where more delicate and complicated instruments are impractical [1].

The other bubble properties such as bubble natural oscillation frequency, rising velocity and shape have been used for interpreting bubble and liquid characteristics in bubble columns $[2,3]$. However, the method with these bubble properties is very complicated in terms of apparatus and calculation. For instance, Sinha [3] has developed a pattern of apparatus and methods for measuring properties of bubbles that can be used for liquid properties/characteristics' determination. These liquid properties are density and surface tension. The apparatus he used was a cylindrical transducer and Doppler probe as the invasive and active method. A non-invasive method has also been developed where a ring piezometer transducer/cavitation transducer was attached externally to the container wall. A syringe was used for injecting air into the liquid bulk which is placed vertically at the container bottom. He used bubble properties (oscillation frequency [4], terminal velocity [5] and oscillation of shape mode [6] to calculate liquid density and surface tension.

Boyd and Varley [7] commented that other techniques such photography and conductivity probes used to measure bubble properties such as gas hold-up and size would not be suitable for application in industries; this is due to the limitation of the visualisation and the intrusive techniques to liquids involved which can foul the probes. On the other hand, AE monitoring is relatively noninvasive and is a rapid measurement technique. In their investigation of acoustic emission measurement of low velocity plunging jets to monitor bubble size, they found that larger bubbles resulted from increasing the height which showed a shift to lower frequency in the spectra.

Leighton et al. [8] employed a Gabor transform time-frequency signal analysis technique to determine bubble size in their investigation of bubble entrainment and bubble cloud generation under a waterfall, and a plunging jet. Computing the Gabor expansion of a signal is one form of time-frequency analysis. A time-frequency representation via the Gabor coefficients was used to identify the bubble signatures. They used a hydrophone (Bruel \& Kjaer 8104) with flat frequency response from $20 \mathrm{~Hz}$ to $22 \mathrm{kHz}$. They found that peaks occurred at $2 \mathrm{kHz}$ and $700 \mathrm{~Hz}$, which correspond to bubbles of approximately 3 $\mathrm{mm}$ and $9 \mathrm{~mm}$ in diameter respectively oscillating at its natural frequency. Their findings noted that the bigger bubble size showed a lower frequency in the spectra.

Jin and Kim [2] found that the mean frequency of the pressure spectrum decreases with the increase of bubble size. They also correlated dynamic minimum pressure with the radius of curvature and the maximum pressure to the vertical bubble length. In other words, the pressure spectrum is correlated with the bubble properties; particularly bubble size (radius curvature). The pressure variation is a function of bubble properties; size, shape, rising velocity and wake properties, and therefore the bubble characteristics can be determined from the Fourier transform [2]. In addition, the energy dissipation rate which was determined from the pressure spectrum was found to increase with the growth of the bubble radius. In their investigation on bubble properties and spectral 
analysis of a single bubble in water, it was found that large bubbles have low peak frequency in the pressure spectrum. Their findings agree with those of Boyd and Varley [7]

\section{Experimental apparatus}

This experiment employed two apparatus. The first apparatus was a square column filled with water. The second apparatus was a cylinder column filled with water $(1 \mathrm{Cp})$ and salt-water $(2 \mathrm{Cp})$ to show the effect of liquid viscosity on the emission of bubble burst.

\subsection{Apparatus 1}

The apparatus (1) used for $\mathrm{AE}$ detection in this investigation are shown in figures 1 (schematic diagram), 2 and 3. A bubble rig was filled with water. A manifold

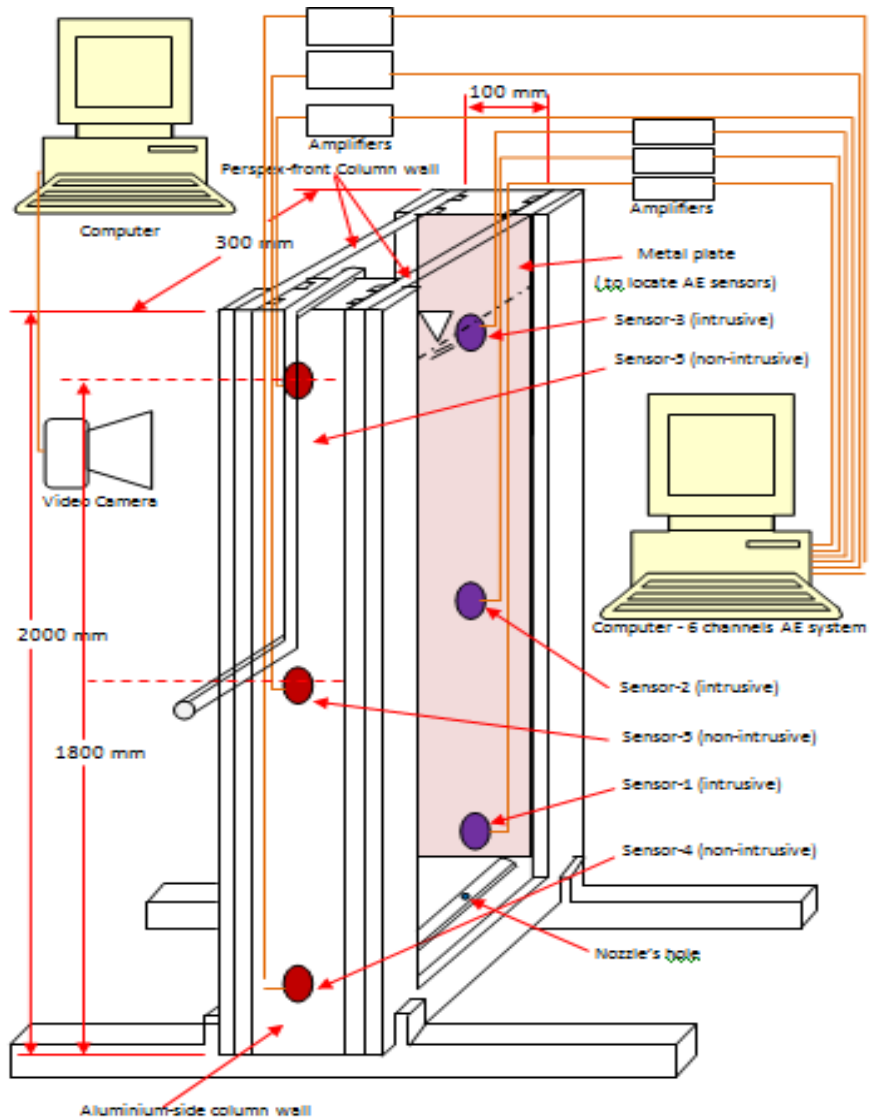

Figure 1: $\quad$ Schematic diagram of apparatus 1. 
pipe consists of a vertical nozzle fixed to the bottom of bubble rig, see figure 2 . Air has been supplied to the manifold by a compressed cylinder. A single bubble was released from the nozzle when the valve was gently opened. Four sizes of nozzle were used in this investigation; 1.4, 2.8, 5.6 and $8.4 \mathrm{~mm}$ internal holediameter. It was assumed that the bubble created using these nozzles is equivalent to the nozzles' internal hole-diameter.

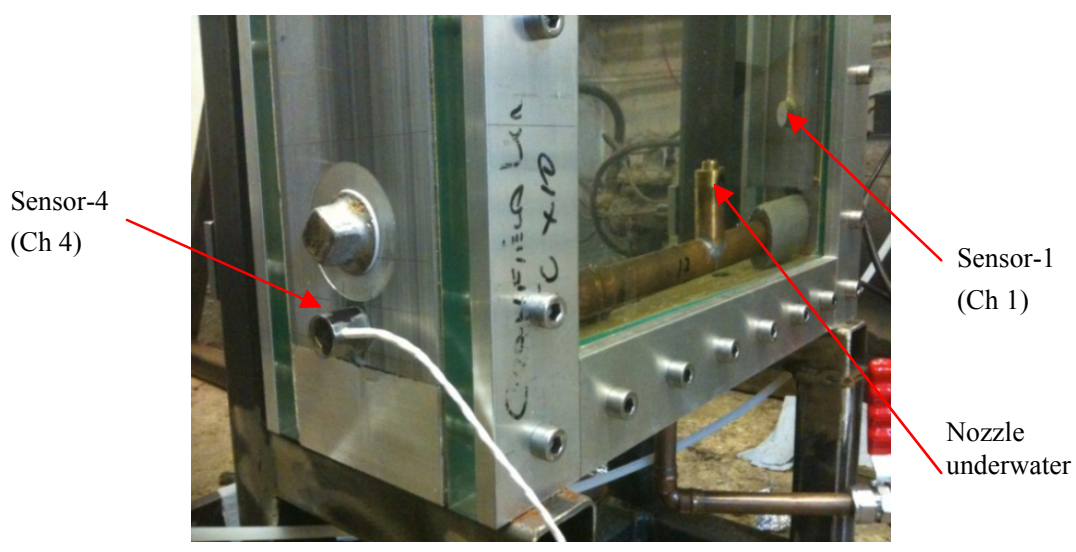

Figure 2: $\quad$ Bubble formation mechanism at the bottom of bubble rig.

Sensors 3 and 4 were mounted onto the column intrusively and nonintrusively to detect bubble burst emissions, see figure 3. Broadband AE transducers (Physical Acoustic Corporation type Wideband Differential, WD) with an operating frequency range of $100-750 \mathrm{kHz}$ and a pre-amplification at 40 $\mathrm{dB}$ was applied. The sampling rate for acquisition of $\mathrm{AE}$ waveforms was set at 2 $\mathrm{MHz}$.

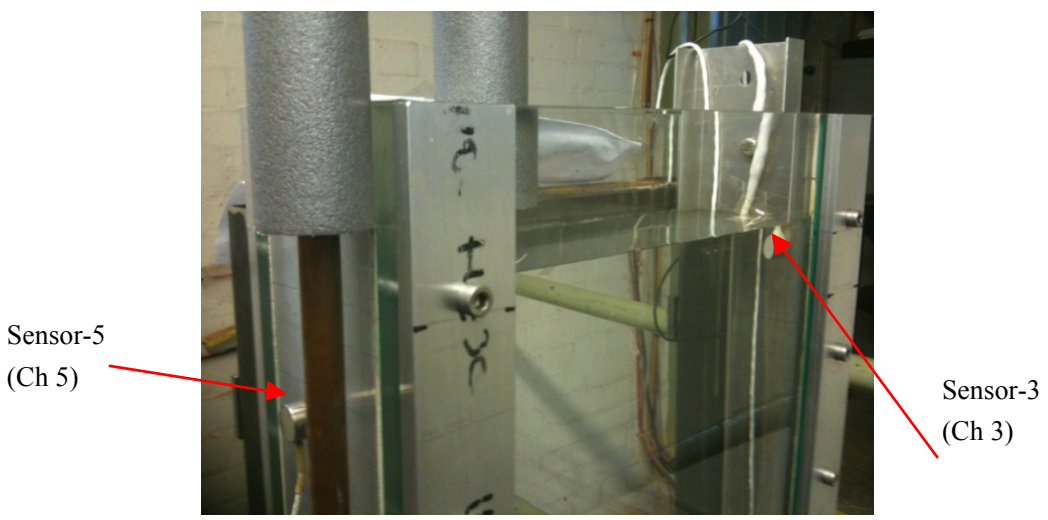

Figure 3: AE sensors mounted at the top (free surface) of bubble rig to detect the emission of bubble burst. 


\subsection{Apparatus 2}

The schematic diagram of apparatus (2) employed for AE measurements is shown in figures 4 . The rig consists of a bed column filled with a fluid. An AE sensor was placed just beneath the free surface of the fluid to detect the emission of bubble burst at free surface. The column was made of Perspex pipe and was $150 \mathrm{~mm}$ in diameter with a height of $1500 \mathrm{~mm}$. The transducers had an operating frequency of $100-750 \mathrm{kHz}$ and a pre-amplification at $60 \mathrm{~dB}$ was applied. The sampling rate for acquisition of $\mathrm{AE}$ waveforms was set at $2 \mathrm{MHz}$. A single bubble was created with a syringe as gas (air) was forced through different sized nozzles (diameters of 1.4, 4.4 and $8.4 \mathrm{~mm}$ ) placed at the bottom of the water column. Two fluid conditions were investigated; plain water with a viscosity of 1 $\mathrm{cP}$ and a fluid with a salt solution and a viscosity of $2 \mathrm{cP}$.

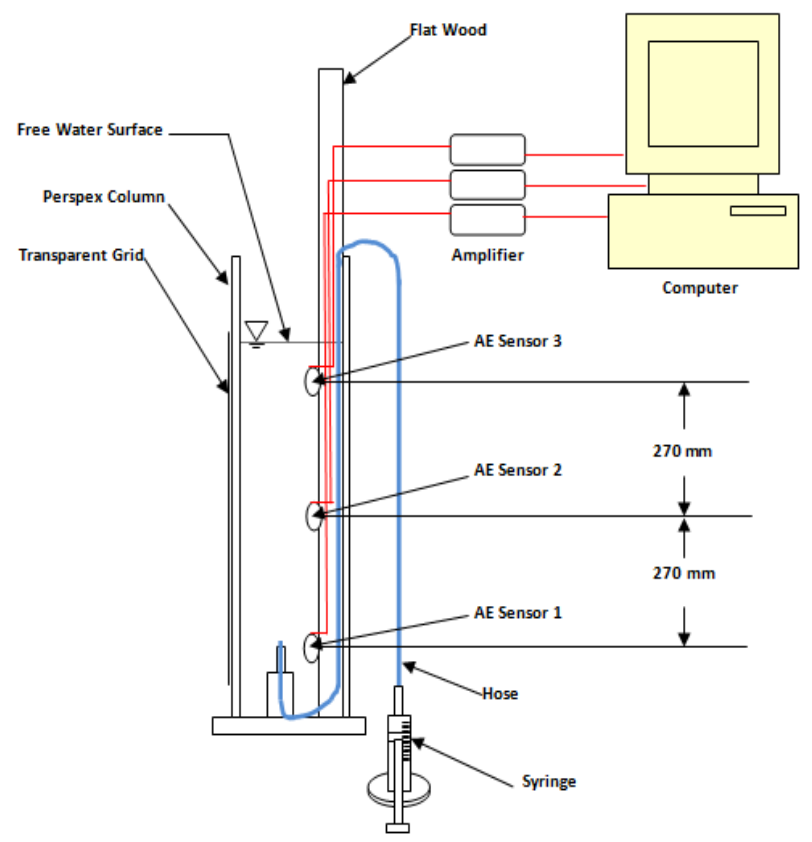

Figure 4: $\quad$ Schematic diagram of apparatus 2.

\section{Experimental results}

\subsection{Test 1(from apparatus 1$)$}

Table 1 shows an example of a signal detected using the AE sensor. The waveform shows a transient upon the bubble burst event and it decays in a very short time $(\sim 10 \mu \mathrm{s})$, see Table 1 . The transient at the waveform plots clearly show that $\mathrm{AE}$ amplitude rises with the increase in bubble size. 
Table 1: $\quad$ AE from a single bubble burst as a function of bubble size.

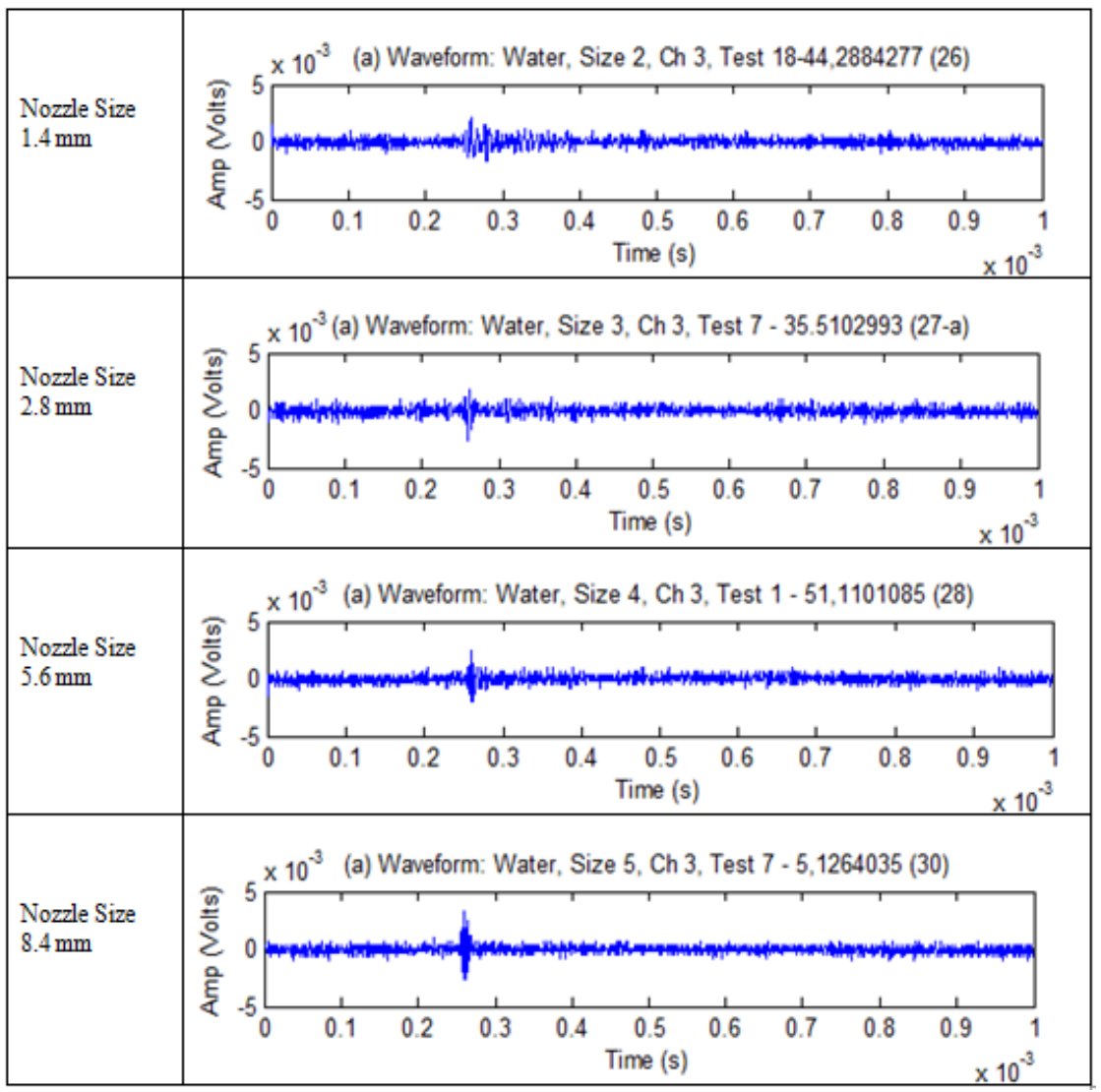

A Fourier analysis highlighted frequency characteristics for all sizes (see Table 2 presenting the average of FFT). The averaged frequency spectra (from 10 samples) of all AE events associated with differing bubble sizes showed an increase in size amplitude across the broad frequency range. Peak amplitude started at $\sim 120 \mathrm{KHz}$ for all sizes. Higher peak amplitude was observed with the bigger nozzle/bubble size. It was found that the peak amplitude at $120 \mathrm{kHz}$ grew with the increasing bubble size. Peak amplitude at $120 \mathrm{kHz}$ for respective sizes $1.4,2.8,5.6$ and $8.4 \mathrm{~mm}$ were $0.5 \times 10^{-5}, 0.6 \times 10^{-5}, 0.7 \times 10^{-5}$ and $1.5 \times 10^{-5}$ Volts. Table 3 presents the summary of peak amplitude comparison at a frequency of $120 \mathrm{kHz}$ for all bubble/nozzle sizes. 
Table 2: $\quad$ Frequency spectra of data acquired by sensor-3 as a function of bubble size.

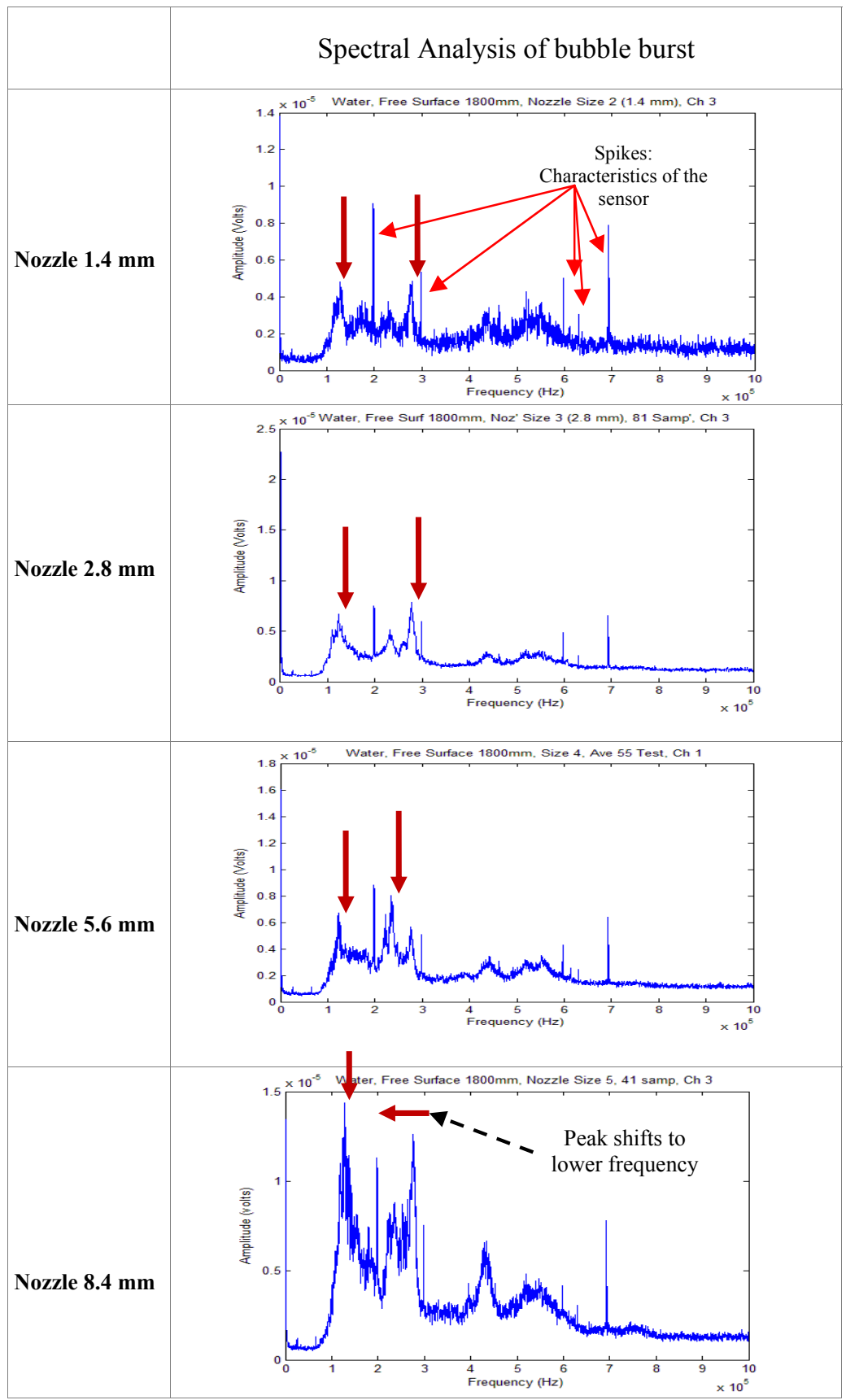


Table 3: $\quad$ Comparison of peak amplitude at frequency $120 \mathrm{KHz}$ for all sizes.

\begin{tabular}{|c|c|c|c|c|}
\hline & Size $1.4 \mathrm{~mm}$ & Size $2.8 \mathrm{~mm}$ & Size $5.6 \mathrm{~mm}$ & Size $8.4 \mathrm{~mm}$ \\
\hline Peak & & & & \\
amplitude & $0.5 \times 10^{-5}$ & $0.6 \times 10^{-}$ & $0.7 \times 10^{-5}$ & $1.5 \times 10^{-5}$ \\
at $120 \mathrm{kHz}$ & Volts & ${ }^{5}$ Volts & Volts & Volts \\
\hline
\end{tabular}

The FFT plot in Table 2 shows that the peak amplitude occurs at the same frequency. This indicates that peak amplitude can be used as a parameter for correlation with bubble size at burst event at free surface. A very close inspection of peak amplitude value at frequency $120 \mathrm{kHz}$ for the size of bubble burst that generated from nozzle sizes $1.4,2.8$ and $5.6 \mathrm{~mm}$ implies that there is not much difference in size generated from those nozzle sizes. However, peak amplitude from the frequency spectrum of nozzle size $8.4 \mathrm{~mm}$ shows an obvious difference value which indicates a big difference of bubble size generated, compared with the previous three bubbles.

Another indicator can be seen in the FFT plot which can be used to indicate that the bubble size is the shift of frequency corresponding to the size of bubble. For nozzle sizes 1.4 and $2.8 \mathrm{~mm}$ it is noted that the peak occurs at $280 \mathrm{kHz}$. The peak shifts to $240 \mathrm{kHz}$ for size $5.6 \mathrm{~mm}$. For the bigger size $8.4 \mathrm{~mm}$, the peak more obviously shifts to the left at the lower frequency $(120 \mathrm{kHz})$. This agrees with the results obtained by previous researchers (Jin and Kim [2]; Pandit et al. (1992); Leighton et al. [8]; Boyd and Varley [7]) where large bubbles have a low peak frequency in the pressure spectrum.

Some spikes in the FFT plot can be seen in all plots for every bubble size (Table 2) which actually result from the characteristics of the AE sensor used. The spikes exist at the same frequency. There are 5 spikes identified, as shown by the arrows in Table 2 .

\subsection{Test 2 (from apparatus 2: Effect of liquid viscosity on bubble burst emission}

The results from test 2 (see Table 4) generally show the same trend as the results from test 1 (see Table 2) where the bigger the size, the higher the amplitude in pressure spectra. Also, it is noted that a shift in the peak in the bubble pulse range to a lower frequency as nozzle size increases, suggests that the bubble size increases correspondingly and this concurs with visual observations of larger bubbles being formed at bigger nozzle sizes. 
Table 4: $\quad$ Average frequency spectra of bubble bursts at free surface.

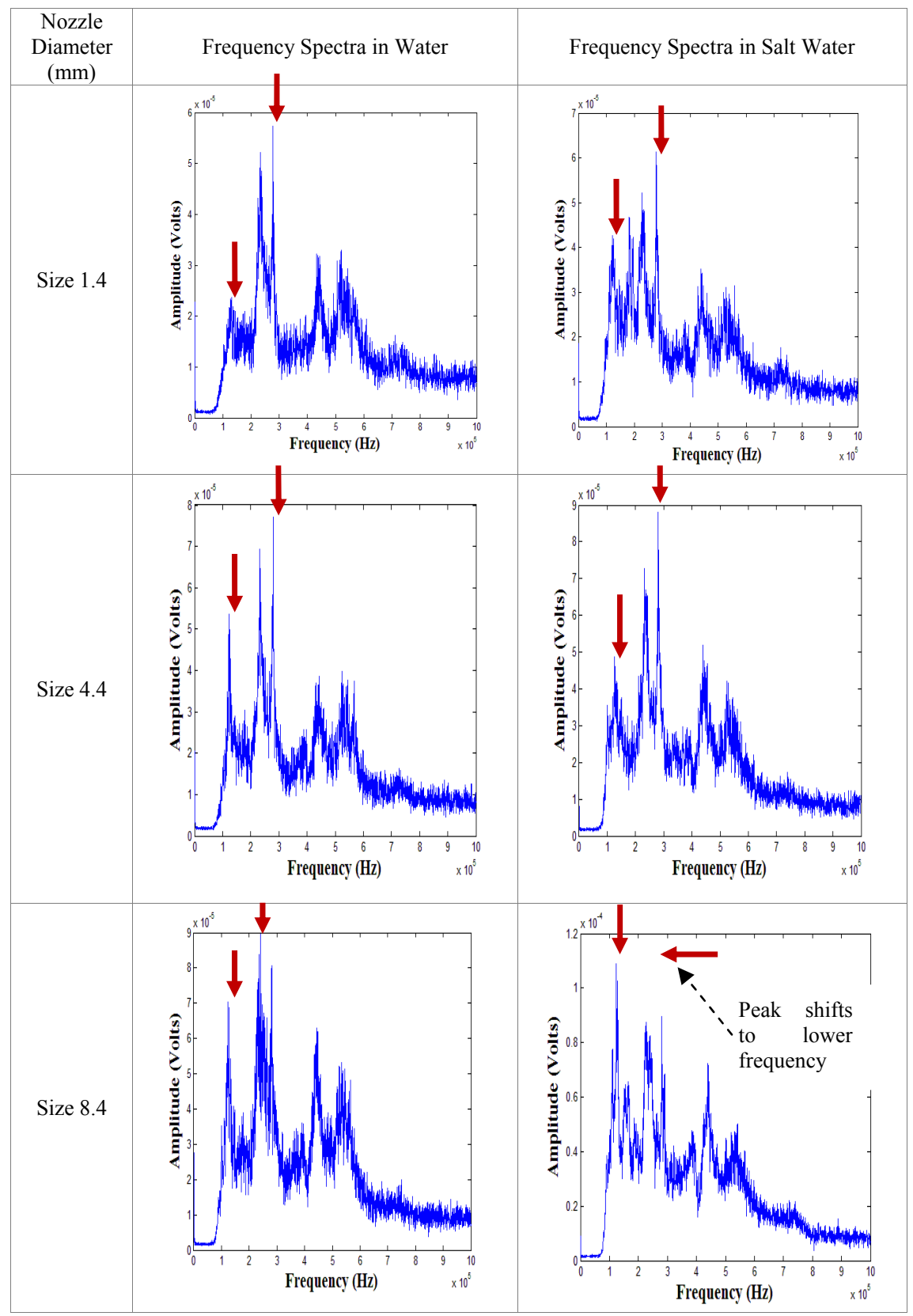


Table 5 shows the comparison of peak amplitude at frequency $120 \mathrm{kHz}$ and $280 \mathrm{kHz}$ for both liquid conditions; water and salt-water. It is noted that peak amplitude at a higher viscosity (salt-water, $2 \mathrm{Cp}$ ) is higher than lower viscosity (water, $1 \mathrm{Cp}$ ). For nozzle sizes 1.4 and $4.4 \mathrm{~mm}$, peak occurs at the same frequency, $280 \mathrm{kHz}$. However, for nozzle size 8.4, it is found to shift to the left to a lower frequency; in water peak frequency shifts to $220 \mathrm{KHz}$, while in saltwater it shifts to $120 \mathrm{KHz}$.

Table 5: $\quad$ Comparison of peak amplitude at frequency $120 \mathrm{KHz}$ for all sizes in water and salt-water.

\begin{tabular}{|c|c|c|c|}
\hline & Size $1.4 \mathrm{~mm}$ & Size $4.4 \mathrm{~mm}$ & Size $8.4 \mathrm{~mm}$ \\
\hline $\begin{array}{c}\text { Peak amplitude at } \\
120 \mathrm{kHz} \text { in Water }\end{array}$ & $2.5 \times 10^{-5}$ Volts & $5.5 \times 10^{-5}$ Volts & $7.0 \times 10^{-5}$ Volts \\
\hline $\begin{array}{c}\text { Peak amplitude at } \\
280 \mathrm{kHz} \text { in Water }\end{array}$ & $5.8 \times 10^{-5}$ Volts & $7.8 \times 10^{-5}$ Volts & $9.0 \times 10^{-5}$ Volts \\
\hline $\begin{array}{c}\text { Peak amplitude at } \\
120 \mathrm{kHz} \text { in Salt- }\end{array}$ & $4.3 \times 10^{-5}$ Volts & $4.8 \times 10^{-5}$ Volts & $11.0 \times 10^{-5}$ Volts \\
\hline $\begin{array}{c}\text { Peak amplitude at } \\
280 \mathrm{kHz} \text { in Salt- } \\
\text { Water }\end{array}$ & $6.2 \times 10^{-5}$ Volts & $9.0 \times 10^{-5}$ Volts & $9.0 \times 10^{-5}$ Volts \\
\hline
\end{tabular}

\section{Conclusions}

Increasing the size of bubble burst at free surface has been observed with a shift to lower frequency in the spectra. This experiment demonstrated that the size of bubble burst at free surface was inversely proportional to frequency.

The acoustic frequency was related to the bubble size, and liquid viscosity on acoustically determined bubble size has been demonstrated. This gives an indication that bubble size can be determined from the calibrated peak amplitude and frequency of a single bubble burst at the frequency spectra. However, this is not an easy task and really needs a lot of correlation tasks before becoming well established as we know that a spectral analysis would be biased unless a correction is introduced [1]. Correlations include bubble properties, liquid properties and the distance of the source (bubble burst location) to the $\mathrm{AE}$ sensor. 


\section{References}

[1] Manasseh, R., and Chanson, H., Void-Fraction and Acoustic Characteristics of Gas Bubbles Entrained by a Circular Plunging Jet. In: 4th International Conference on Multiphase Flow, ICMF'01, New Orleans, USA, pp. 1-12, 2001.

[2] Jin, G.T. and Kim S.D., Bubble properties and pressure fluctuations of a single bubble in water. Journal of Chemical Engineering of Japan, Vol 23, No 5, pp. 523-529, 1990.

[3] Sinha, N.N., Characterization of Liquids Using Gas Bubbles. United States Patent No: US 7,010,962 B2. Mar. 14, 2006.

[4] Minnaert, M., On Musical Air-Bubbles and the Sounds of Running Water. Philosophical Mag. 16, pp. 235-248, 1993.

[5] Kellerman, H., Juttner, K. and Kreysa, G., Dynamic Modelling of Gas-Holdup Electrolyte Systems. Journal of App Electrochemistry, 28, pp. 311-319, 1998.

[6] Strasberg, M., Gas Bubbles as Source of Sound in Liquids. The Journal of the Acoustical Society of America, 28, 1, pp. 20-26, 1956.

[7] Boyd, J.W.R and Varley, J.., Acoustic Emission Measurement of Low Velocity Plunging Jets to Monitor Bubble Size. Chemical Engineering Journal, 97, pp. 11-25, 2004.

[8] Leighton, T.G., White, P.R., and Schneider, M.F. The detection and dimension of bubble entrainment and comminution. J. Acoust. Soc. Am. 103 (4), pp. 1825-1835. 1998. 